\title{
Interval hypoxic training in complex treatment of Helicobacter pylori-associated peptic ulcer disease ${ }^{\star}$
}

\author{
Khrysyna O. Semen ${ }^{1}$, Olha P. Yelisyeyeva ${ }^{\varpi}$, Danylo V. Kaminskyy ${ }^{3}$, Andriy P. Cherkas ${ }^{1,4}$, \\ Kamelija Zarkovic ${ }^{5}$, O. Lutsyk², Ana Cipak, ${ }^{6}$, Morana Jaganjac ${ }^{6}$ and Neven Zarkovic ${ }^{6}$
}

'Department of Internal Medicine No.1, 2Department of Histology, Cytology, and Embryology, ${ }^{3}$ Department of Organic, Biorganic and Pharmaceutical Chemistry, ${ }^{4}$ Department of Endocrinology, Danylo Halytskyi National Medical University, Lviv, Ukraine; ${ }^{5}$ Division of Pathology, University Hospital Centre "Zagreb", Zagreb, Croatia; 'Division of Molecular Medicine, Institute "Ruđjer Boškovič", Zagreb, Croatia

This study was aimed to demonstrate the efficacy of interval hypoxic training (IHT) in complex treatment of Helicobacter pylori-associated duodenal peptic ulcer disease (DPUD) by parameters of aerobic metabolism and indexes of heart rate variability (HRV). Eighty patients with $H$. pylori-associated DPUD were included into the study, mean age $32 \pm 1.8 \mathrm{yrs}$, duration of the disease up to 10 years $(66.3 \%)$. IHT was modulated using Frolov's hypoxicator (TDI-01) for $\mathbf{3 0}$ days after standard eradication therapy. Daily hypoxic sessions consisted of three one-minute sessions, one two-minute, and one threeminute sessions separated by one-minute intervals of room-air breathing. Use of IHT resulted in more efficient elimination of clinical symptoms, histological hallmarks of inflammation and signs of oxidative stress in glandulocytes of the gastric mucosa as determined by 4-hydroxynonenal accumulation. Moderate prooxidant activity of IHT was demonstrated by the increased level of TBARS and oxidatively modified products, normalization of hydroperoxides, middle mass molecules and atherogenic beta-lipoproteins with simultaneous increase in catalase activity and mild decline of SOD activity. Therefore, IHT appeared to be accompanied by higher intensity of redox reactions and enhanced regeneratory processes in cells and tissues. Significant increase in HRV was also noted. Such changes were associated with reduction of inflammation signs and modulation of the autonomic homeostasis in DPUD patients. In general, use of IHT in complex treatment of $H$. pylori in DPUD patients can be recommended to increase resistance to oxidative stress and to modulate autonomic balance and oxidative homeostasis.

Key words: peptic ulcer, oxidative stress, heart rate variability, interval hypoxic training, oxidative homeostasis

Received: 11 December, 2009; 17 May, 2010; accepted: 04 June, 2010; available on-line: 08 June, 2010

\section{INTRODUCTION}

Because of the great variety of diseases associated with oxidative stress (OS) the search for new remedies with antioxidants properties is currently of tremendous importance. Many pharmacological substances with demonstrated efficacy to control excessive ROS production in vitro frequently do not give the same results in vivo. This is associated mainly with their action on one predominant mechanism of OS development and an inability to improve the coupling between main structures of oxidation, namely, microsomes, peroxisomes, and mitochondria (Denisov \& Afanas'ev, 2005; Jones 2006; Manoli et al., 2007; Packer, 2007). A promising approach is preconditioning when a low intensity challenge is used to increase an organism's resistance to the similar but more severe insults (Arumugam et al., 2006; Das \& Maulik, 2003; Mattson, 2008). To achieve preconditioning effect various types of hypoxic training are frequently used and among them interval hypoxic training (IHT) is the most efficient (Bernardi et al., 2001; Gurusamy et al., 2009).

Theoretical and practical aspects of hypoxic training with various durations of hypoxic exposures and degree of hypoxia have been studied for more than 50 years. However, even nowadays there is no uniform approach to the timing of hypoxic sessions and no agreement on the mechanism of its action (Katayama et al., 2005; Levine, 2002; Morton \& Cable, 2005; Neubauer, 2001; Prabhakar, 2001; Prabhakar et al., 2007). Accumulating evidence shows, that positive effects of hypoxia are clearly associated with the interval ( $4-5$ cycles of hypoxia per session), mild (14-18\% of $\mathrm{O}_{2}$ in hypoxic mixture), and short-time $(<5-10 \mathrm{~min})$ normobaric exposures separated by short (up to $5 \mathrm{~min}$ ) recovery periods. That can be explained by mild to moderate increase in flow of reactive oxygen species (ROS) occurring both during hypoxia and even more so during the reoxygenation periods, which can efficiently induce complex antihypoxic defense mechanisms. Among them the most important include activation of not only antioxidant enzymes and main transcription factors (HIF, ARE) but also energy function of mitochondria (Bell et al., 2005; Giordano, 2005; Manoli et al., 2007). Coordinated involvement of such complex machinery helps the metabolic system to compensate hypoxic influence and to improve its resistance to more severe insults without a marked strain.

IHT denotes repetitive shifts from hypoxia to roomair breathing and its effects are associated, on one hand,

$\star$ e-mail: yelisol@gmail.com

^ The paper was presented at the COST B-35 Work Group 4 Open Workshop "Natural and synthetic antioxidants" September 25-26, 2009, Rzeszów, Poland.

Abbreviations: CAT, catalase; CU, conventional units; DPUD, duodenal peptic ulcer disease; FRR, free radical reactions; HNE, hydroxynonenal; HRV, heart rate variability; HF, high frequency power; IHT, interval hypoxic training; LF, low frequency power; LP, lipoproyein; MMM, middle mass molecules; OMP, oxidatively modified proteins; OS, oxidative stress; ROS, reactive oxygen species; SOD, superoxide dismutase; TBARS, thiobarbituric acid reactive species; TCA, trichloroacetic acid; TP, total power; VLF, very low frequency power. 
with the activation of the mechanisms of signal transduction and expressions of genes involved in the protective and reparative cellular response to the damaging effect of the OS. This effect is initiated by changes in the redox state and can be called indirect or delayed in time. On the other hand, IHT exhibits also an immediate effect associated with fluctuations of superoxide anion, $\mathrm{H}_{2} \mathrm{O}_{2}$, and $\mathrm{O}_{2}$ during free radical reactions in cells and, thus, modulation of antioxidant system activity and resulting improved utilization of oxidative decomposition products (Tymochko et al., 1998; Voeikov, 2005). Moreover, this second pathway causes activation of many antioxidant enzymes, which are oxygen dependent and are inhibited under hypoxic conditions (Bunn \& Schumacker, 1996; Williams 2004; Guzy 2006). Thus, IHT results in improved efficiency of aerobic metabolism, stimulation of regenerative processes, and, consequently, increase in resistance to OS.

Here we studied the efficacy of IHT in patients with $H$. pylori-associated duodenal peptic ulcer disease (DPUD), which is characterized by variable clinical presentation associated with the defect in the mucosal integrity of the duodenum. OS is recognized as an important pathogenetic mechanism of $H$. pylori-related lesions (Malaty 2007; Matthews \& Butler 2005; Suerbaum \& Michetti 2002; Yelisyeyeva et al., 2008). Although infection with $H$. pylori is recognized to be the triggering event in the pathogenesis of DPUD many questions remain unanswered as, for example, why only $10-15 \%$ of infected subjects develop overt ulcer and many other remain asymptomatic bearers, and why the signs of OS and clinical manifestations may persist after the eradication of the microorganism (Everett et al., 2001; Cherkas et al., 2009). Probably the resistance of the patient to $H$. pylori and its adaptive potential play important roles in these processes.

Currently, apart from a search for new antioxidants another important task of biomedical science is search for integrative parameters which would adequately reflect the condition of functional metabolic reserve (Yelisyeyeva et al., 2005; Packer \& Codenas, 2007). One of the readily available and noninvasive methods is heart rate variability (HRV). Its principle is based on the analysis of differences between normal RR intervals in short or long term ECG recordings. Recently, ample literature data have shown connection between HRV and metabolic indexes (Connes et al., 2008; Haensel et al., 2008; Kawada et al., 2009; Pongchaidecha et al., 2009; von Kanel et al., 2009).

The aim of the present research was to study the efficacy of treatment of $H$. pylori-associated DPUD using interval hypoxic training during post-eradication period by evaluation of aerobic metabolism and HRV.

\section{MATERIALS AND METHODS}

Patients and study design. $H$. pylori-positive patients $(n=80$, mean age $32.1 \pm 1.8$ yrs, 48 males and 29 females) with endoscopically proven active DPUD and without other significant illnesses were enrolled into the study and divided into two groups: group 1 consisted of 40 subjects (mean age $32.1 \pm 1.7$ yrs, 24 males, 16 females), while group 2 comprised 37 patients $(31.9 \pm 1.6$ yrs, 24 males, 13 females). Healthy volunteers ( $n=40$, mean age $29.7 \pm 3.5$ yrs, 25 males and 15 females) without any gastrointestinal complaints or other registered health problems served as a control group. Patients from both groups were prescribed triple eradication therapy (Lansoprazole $30 \mathrm{mg}$, Amoxicillin $1000 \mathrm{mg}$, and Clarithromycin $500 \mathrm{mg}$ twice per day) for seven days. Later on all subjects were administered Lansoprazole $30 \mathrm{mg}$ once a day for four weeks. No other drugs were allowed during this period. During posteradication period in addition to Lansoprazole group 2 individuals practiced IHT (hypoxicator TDI-01, Russian Federation). One IHT session consisted of five cycles, each of which included hypoxic exposure followed by one-minute reoxygenation with room-air breathing. Hypoxic exposures of the first three cycles lasted one minute, while the duration of the fourth and fifth cycle hypoxic breathing lasted two and three minutes, respectively. Thus, total time of hypoxia during an IHT session was eight minutes. The training was performed on daily basis (at bedtime hours) for four weeks. Before and $30( \pm 3)$ days after the completion of the antimicrobial treatment patients underwent clinical, endoscopic and histological examination, determination of 4-hydroxynonenal (HNE) in the gastric mucosa, study of HRV, and evaluation of biochemical indexes characterizing pro/antioxidant balance in the blood. All investigations and blood sampling were performed in the morning hours between 9 a.m. and 11 a.m. before meal. Patients and healthy volunteers were asked to restrain from smoking and drinking alcohol at the days when blood collections and other studies were performed. The design of the study was approved by the local Ethics Committee at Lviv National Medical University and informed consent was obtained from all patients and healthy volunteers.

Histology and assessment of $\boldsymbol{H}$. pylori infection. For histological examination two biopsy specimens were obtained endoscopically from antrum and two from corpus of the stomach in all DPUD patients as it is known that $H$. pylori lives predominantly in these gastric parts. Because this microorganism is rarely observed in the duodenum while the risk of complications (perforation, haemorrhage) is much higher no samples from this region were obtained.

The biopsy specimens were immediately fixed in buffered $10 \%$ formalin, then dehydrated in ethanol and embedded in paraffin, cut into $5-\mu \mathrm{m}$ thick sections and examined with haematoxylin-eosin and modified Giemsa staining. Histologically, $H$. pylori infection was considered as negative if $H$. pylori was absent in all biopsies obtained from one patient and positive if it was found in at least one sample. Additionally, one antral biopsy specimen was taken for rapid urease test. Inflammation, presence of $H$. pylori, glandular atrophy and intestinal metaplasia were classified qualitatively as negative (0) or positive (1); and semi-quantitatively into four grades according to updated Sydney System as follows: 0, none; 1, mild; 2, moderate, and 3, severe.

Determination of HNE-histidine conjugates. Representative paraffin blocks obtained only from patients with successful eradication of $H$. pylori before and after treatment were further used for immunohistochemical staining: one slice of each specimen was cut into $5-\mu \mathrm{m}$ thin sections, mounted on a slide coated with (3-aminopropyl)triethoxysilane, deparaffinated in xylene and rehydrated through a series of ethanol. Immunohistochemistry for HNE-modified proteins was carried out as described before (Yelisyeyeva et al., 2008; Cherkas et al., 2009) using monoclonal antibodies obtained from culture medium of clone 'HNE $1 \mathrm{~g} 4$ ' produced by a fusion of Sp2-Ag8 myeloma cells with B-cells of a BALB-c mouse immunized with HNE-modified keyhole limpet 
hemocyanine (Waeg et al., 1996). The antibody is specific for the HNE-histidine epitope in HNE-protein (peptide) conjugates and gives only $5 \%$ cross-reactivity with HNE-lysine and 4\% with HNE-cysteine.

Immunohistochemistry was done in a three-step procedure as described before using LSAB kit (DAKO, Denmark) where the first step was incubation with antiHNE monoclonal antibodies (dilution $1: 10$ ) for $2 \mathrm{~h}$ in humid chambers at room temperature. The second step was incubation with biotinylated secondary goat antimouse and anti-rabbit immunoglobulins (AB2) for 30 min. The third step was incubation with streptavidinperoxidase for $30 \mathrm{~min}$. Finally, the reaction was visualized with $\mathrm{DAB}$ (3.3-diaminobenzidine tetrahydrochloride in organic solvent; DAKO, Denmark) after $10 \mathrm{~min}$ of incubation. Negative control was done on one histological slice of the same tissue, without application of the HNE-histidine specific monoclonal antibodies. The intensity and distribution of the HNE-immunostaining in the gastric mucosa from antrum and corpus of the stomach were evaluated semi-quantitatively. The absence of immunopositivity in the cytoplasm and nuclei of glandular epithelial cells was marked with (0), while with (1) we marked weak immunopositivity in less than $25 \%$ of the cells, with (2) medium immunopositivity in 25-50\% of cells and, finally, with (3) strong immunopositivity in more than $50 \%$ of cells. In superficial and foveolar epithelium as well as in lamina propria of the gastric mucosa we distinguished only positive (1) and negative (0) immunostaining. All immunohistochemical analyses were done by a pathologist experienced in the HNE immunohistochemistry without prior knowledge of the study group design.

Catalase (CAT) activity was determined spectrophotometrically (Korolyuk et al., 1998). The reaction was initialized by adding into the incubation medium $(2 \mathrm{ml}$ of $0.03 \%$ solution of $\left.\mathrm{H}_{2} \mathrm{O}_{2}\right) 0.1 \mathrm{ml}$ of serum. The duration of this reaction was $10 \mathrm{~min}$ at room temp. The reaction was terminated by rapid adding of $1.0 \mathrm{ml}$ of $4 \%$ ammonium molybdate solution in $12.5 \mathrm{mM} \mathrm{H}_{2} \mathrm{SO}_{4}$ and $1 \mathrm{ml}$ $125 \mathrm{mM} \mathrm{H}_{2} \mathrm{SO}_{4}$. Control assay instead of serum included $0.1 \mathrm{ml}$ of distilled water. All samples were centrifuged at $3000 \mathrm{rpm}$ for $5 \mathrm{~min}$. The absorbance of the obtained solution was measured at $410 \mathrm{~nm}$ and was compared with that of the control. CAT activity was calculated by the formula: $\mathrm{A}=\left(\mathrm{E}_{\text {control }}-\mathrm{E}_{\text {studied }}\right) /(\mathrm{V} / \mathrm{tkl})$, where $\mathrm{A}$, CAT activity $\left(\mu \mathrm{mol} \mathrm{H}_{2} \mathrm{O}_{2} / \mathrm{ml} \cdot \mathrm{h}\right) ; \mathrm{E}_{\text {control }}$ and $\mathrm{E}_{\text {studied }}$, absorbance of control and study samples; $\mathrm{V}$, volume of the sample $(0.1 \mathrm{ml})$; $\mathrm{t}$, time of incubation $(600 \mathrm{~s}) ; \mathrm{k}$, coefficient of $\mathrm{H}_{2} \mathrm{O}_{2} \mathrm{mM}$ absorbance $\left(\mathrm{k}=22.2 \times 10^{3} \mathrm{mM}^{-1} \mathrm{~cm}^{-1}\right)$; 1 , length of the absorbance cell $(1 \mathrm{~cm})$. Finally, $\mathrm{A}=0.27$ $\left(\mathrm{E}_{\text {control }}-\mathrm{E}_{\text {studied }}\right)\left[\mu \mathrm{mol} \mathrm{H}_{2} \mathrm{O}_{2} / \mathrm{ml} \cdot \mathrm{h}\right]$.

Superoxide dismutase (SOD) activity was assessed by its ability to dismutate superoxide produced during quercetin auto-oxidation in an alkaline medium $(\mathrm{pH}=10.0)$ (Kostyuk et al., 1990). Briefly, $1.0 \mathrm{ml}$ of $\mathrm{C}$ reagent was mixed with $0.1 \mathrm{ml}$ diluted hemolyzed blood $(1: 1000)$. C reagent was made ex tempore (mixture of equal volumes of $0.1 \mathrm{M} \mathrm{K}, \mathrm{Na}$-phosphate buffer, $\mathrm{pH}=7.8$ and $0.08 \mathrm{M}$ EDTA, $\mathrm{pH}$ of $\mathrm{C}$ reagent was adjusted to 10.0 by adding tetramethylenediamine. Distilled water $(0.1 \mathrm{ml})$ was added to control vials instead of serum. The total volume of all samples was brought up to $2.4 \mathrm{ml}$ using distilled water. The reaction was initiated by adding $0.1 \mathrm{ml}$ of quercetin $(1.4 \mu \mathrm{M}$ in dimethyl sulfoxide). Absorbance at $406 \mathrm{~nm}$ was measured immediately and after $20 \mathrm{~min}$. The SOD activity of the blood was calculated by the formula: $A=\left(\left(E_{406}^{\prime}-E_{406}^{\prime \prime}\right) / E_{406}^{\prime}\right) 100 \%$, where A, SOD activity ( $\%$ of inhibition of quercetin auto-oxidation); $\mathrm{E}_{406}^{\prime}$, change in the absorbance after 20 min in the control vial; $\mathrm{E}_{406}^{\prime \prime}$, change in the absorbance after $20 \mathrm{~min}$ in the studied vial.

Lipid peroxidation products were assayed as thiobarbituric acid reactive species (TBARS) (Timirbulatov \& Seleznev, 1986). Briefly, $0.2 \mathrm{ml}$ of serum was mixed with $3.0 \mathrm{ml}$ of $10 \mathrm{mM}$ phosphate buffer containing $125 \mathrm{mM} \mathrm{KCl}, \mathrm{pH}=7.4$. Next, $0.5 \mathrm{ml}$ of $1 \mathrm{mM}$ $\mathrm{KMnO}_{4}$ was added. After $10 \mathrm{~min}$ incubation at room temp. $0.5 \mathrm{ml}$ of $10 \mathrm{mM} \mathrm{FeSO}_{4}$ was added and incubation continued for $10 \mathrm{~min}$. Then $0.5 \mathrm{ml}$ of $10 \mathrm{mM} \mathrm{FeSO}_{4}$ was added followed by incubation for $5 \mathrm{~min}$, which was performed twice. The reaction was terminated with 1.0 $\mathrm{ml}$ of $20 \%$ trichloroacetic acid (TCA). All samples were subsequently centrifuged for $10 \mathrm{~min}$ at $1500 \mathrm{rpm}$. Supernatant $(2.0 \mathrm{ml})$ was transferred to a vial with $0.5 \mathrm{ml}$ of 1 $\mathrm{M} \mathrm{HCl}$ and $1.0 \mathrm{ml}$ of $0.5 \%$ thiobarbituric acid and incubated for $20 \mathrm{~min}$ at $95-100^{\circ} \mathrm{C}$. Samples were cooled and TBARS were extracted with butanol $(3.0 \mathrm{ml})$ and centrifuged at $3000 \mathrm{rpm}$ for $15 \mathrm{~min}$. The absorbance of the butanol lipid extraction products was recorded at 532 $\mathrm{nm}$ against the control. Concentration of TBARS was calculated as $\mathrm{C}=\mathrm{EVK} / \mathrm{AW}$, where: $\mathrm{C}$, concentration of TBARS, $(\mu \mathrm{mol} / \mathrm{ml})$ in terms of malonic dialdehyde; $\mathrm{E}$, absorbance at $532 \mathrm{~nm}$; $\mathrm{V}$, volume of butanol $(3.0 \mathrm{ml})$; $\mathrm{K}$, coefficient 2.75 (for $2.0 \mathrm{ml}$ of supernatant); $\mathrm{A}$, molar absorption coefficient $\left(A=0.156 \times 10^{6} \mu \mathrm{M}^{-1} \cdot \mathrm{cm}^{-1}\right.$ for TBARS in terms of malonic dialdehyde); W, volume of the studied material $(0.2 \mathrm{ml}$ serum). Finally, $\mathrm{C}=274.4 \times \mathrm{E}$ $\mu \mathrm{mol} / \mathrm{ml}$.

Oxidatively modified proteins (OMP) were measured by the reaction between the oxidized carbonyl amino-acid residues and 2,4-dinitrophenylhydrazine (2,4$\mathrm{DNFH}$ ) with formation of 2,4-dinitrohydrazones, which were determined spectrophotometrically (Dubinina et al., 1995). To precipitate the proteins $0.1 \mathrm{ml}$ of serum was mixed with $0.9 \mathrm{ml}$ of $20 \%$ TCA and $1.0 \mathrm{ml}$ of $0.1 \mathrm{M}$ 2,4-DNFH in $2 \mathrm{M} \mathrm{HCl}$. The control vial included 1.0 $\mathrm{ml}$ of $2 \mathrm{M} \mathrm{HCl}$ instead of 2,4-DNFH. All samples were incubated for one hour and the sediment was mixed 3-4 times. Tubes were centrifuged for $15 \mathrm{~min}$ at 3000 $\mathrm{rpm}$. The sediment was washed thrice with ethanol/ethylacetate solution $(1: 1)$ for the extraction of lipids and 2,4-DNFH which did not react with the carbonyl groups of the oxidized proteins. The obtained sediment was air dried and dissolved in $2.5 \mathrm{ml}$ of $8 \mathrm{M}$ urea. To achieve better sediment dissolution 1-2 drops of $2 \mathrm{M} \mathrm{HCl}$ were added and the mixture was heated in boiling water for $5 \mathrm{~min}$. The absorbance of neutral $\left(\mathrm{E}_{370}\right)$ and alkaline $\left(\mathrm{E}_{430}\right)$ phases of 2,4-dinitrophenylhydrazones were measured at $370 \mathrm{~nm}$ and $430 \mathrm{~nm}$, respectively. The concentration of OMP products is expressed in $\mathrm{CU} / \mathrm{ml}$ of serum and calculated by the formula $\mathrm{C}=\mathrm{E}_{370}(\mathrm{Vp} \times \mathrm{Vs})$, where $\mathrm{C}$, concentration of neutral phase 2,4-DNFH in $\mathrm{CU} / \mathrm{ml}$ of serum; $\mathrm{Vp}=2.5 \mathrm{ml}$ (volume of the reacting mixture); $\mathrm{Vs}=0.1 \mathrm{ml}$ (volume of the studied serum). After that the findings were substituted into the formula $\mathrm{C}=25 \times \mathrm{E}_{370}$, in $\mathrm{CU} / \mathrm{ml}$ (for neutral 2,4-dinitrohydrazones); $\mathrm{C}=25 \times \mathrm{E}_{430}$, in $\mathrm{CU} / \mathrm{ml}$ (for alkaline 2,4-dinitrohydrazones).

Middle mass molecules (MMM) is a heterogenic fraction of oligopeptides with molecular mass of 300 5000 Da which include hormones, neuropeptides, mediators of immune and inflammatory response, products of incomplete proteolysis, regulators of gene expression, glycopeptides and nucleopeptides, which explains the high biologic activity of MMM. 
MMM are determined in the supernatant after precipitation of high molecular mass peptides and proteins with TCA with subsequent centrifuging (Kamyshnikov, 2000a). The level of MMM (which are not precipitated by TCA but carry in their structure peptide bonds and aromatic amino-acids) is determined based on their UV absorbance. Two fractions of MMM are of greatest importance: 1) those that mainly do not contain aromatic amino-acids moieties (determined of $254 \mathrm{~nm}$ ), and 2) those that contain mainly aromatic amino-acids moieties (determined of $280 \mathrm{~nm}$ ). Procedure: $0.4 \mathrm{ml}$ of serum and $0.25 \mathrm{ml}$ of $10 \%$ TCA were mixed and centrifuged at $3000 \mathrm{rpm}$ for $20 \mathrm{~min}$, then $0.3 \mathrm{ml}$ of supernatant was transferred to another vial and total volume was increased to $3.0 \mathrm{ml}$ with distilled water. Absorbance of each sample was studied at $254 \mathrm{~nm}$ and $280 \mathrm{~nm}$. Levels of $\mathrm{MMM}_{254}$ and $\mathrm{MMM}_{280}$ are given in CU of absorbance at the corresponding wavelengths.

The content of MMM may vary depending upon the disorder, its complications, conditions of metabolism, compensatory reactions, and general adaptive potential of an organism.

Determination of hydroperoxides was based on the optical density of the lipid phase of the serum at $233 \mathrm{~nm}$ (Kamyshnikov, 2000b). Serum $(0.2 \mathrm{ml})$ was mixed with 4 $\mathrm{ml}$ of heptane/iso-propanol mixture $(1: 1)$ and 1-2 drops of $90 \mathrm{mM}$ EDTA (inhibitor of free radical oxidation). The samples were shaken for $30 \mathrm{~min}$ on a lab shaker at a standard regimen. Then, $2 \mathrm{ml}$ of heptane and $1 \mathrm{ml}$ of $0.01 \mathrm{M} \mathrm{HCl}$ were added for better lipid extraction and separation of the heptane and iso-propanol phases. Samples were carefully mixed and left at room temp. for $30-40 \mathrm{~min}$. Into the control tube instead of serum 0.2 $\mathrm{ml}$ of distilled water was added. To measure the optical density of the lipid extracts the superficial heptane phase was used. The calculation for the concentration of lipid hydroperoxides was performed by the formula: $\mathrm{C}=\left(\mathrm{D}_{233} \times \mathrm{Ve}\right) / \mathrm{Vp}$, where $\mathrm{C}$, hydroperoxides level, in $\mathrm{CU} / \mathrm{ml} ; \mathrm{D}_{233}$, absorbance at $233 \mathrm{~nm} ; \mathrm{Ve}=4 \mathrm{ml}$, volume of the heptane extraction phase; $\mathrm{Vp}=0.2 \mathrm{ml}$, volume of the studied serum. After the experimental values were substituted into the formula, the following result was obtained: $\mathrm{C}=20 \times \mathrm{D}_{233}$, in $\mathrm{CU} / \mathrm{ml}$. Normal values for hydroperoxides range from 1.0 to $1.6 \mathrm{CU} / \mathrm{ml}$.

The level of $\beta$-LP was determined by turbidimetric assay with spectrophotometric completion (Kamyshnikov, 2000c). In the presence of $\mathrm{CaCl}_{2}$ and heparin the colloid protein stability is affected which causes precipitation of $\beta$ - and pre- $\beta$-lipoproteins with development of insoluble heparin complex (turbid dispersed solution is formed). The concentration of apo- $\beta$-lipoproteins in serum can be determined by the turbidity. The absorbance was measured at $700 \mathrm{~nm}$ in a absorbance cell $(1=1 \mathrm{~cm})$. Two millilitres of $25 \mathrm{mM} \mathrm{CaCl}_{2}$ was mixed with $0.2 \mathrm{ml}$ of serum and absorbance was studied at $700 \mathrm{~nm}$ and compared to that obtained for water. Subsequently $0.04 \mathrm{ml}$ of heparin $(100 \mathrm{IU} / \mathrm{ml})$ was added, gently mixed and after 4 min the absorbance of the turbid solution was determined at the same wavelength. The amount of $\beta$-LP was calculated from the difference of absorbance values (before and after heparin), multiplied by 100 . $C=\left(D_{2}-D_{1}\right) \times 100$, where $C$, amount of $\beta-\mathrm{LP}$, in CU; $\mathrm{D}_{2}$, absorbance of the turbid solution after reaction with heparin; $\mathrm{D}_{1}$, absorbance of the solution before reaction. Normal values of $\beta$-LP range from 35 to 55 CU.

Study of heart rate variability. The short-time records of ECG were performed using a computer elec- trocardiograph "VNS-Micro" (Neurosoft ${ }^{\circledR}$, Russian Federation). During quite wakefulness after $20 \mathrm{~min}$ of rest, patients were asked to stay supine quietly for $5 \mathrm{~min}$ for stationary condition HRV recording (clinostasis); afterwards they were asked to stand up rapidly and remained in the standing position for 6 min (orthostatic test). RR intervals were determined with a sampling frequency of $2 \mathrm{kHz}$ and were analyzed with "Poly-Spectrum" (Neurosoft ${ }^{\circledR}$, Russian Federation) software designed according to HRV standards (Task Force, 1996). The time-domain indices - standard deviation of normal RR intervals (SDNN), square root of mean squared differences of successive RR interval (RMSSD), and percentage of differences between adjacent normal RR intervals exceeding $50 \mathrm{~ms}$ (pNN50) were determined. Power spectral analysis was performed sequentially with a fast Fourier transformation. The following frequency-domain variables were studied: total power (TP, $0.01 \mathrm{~Hz}$ to $0.4 \mathrm{~Hz}$ ), high frequency power (HF, 0.15 to $0.4 \mathrm{~Hz}$, reflects activity of parasympathetic nervous system), low frequency power (LF, $0.04 \mathrm{~Hz}$ to $0.15 \mathrm{~Hz}$, reflects predominantly activity of sympathetic nervous system), and very low frequency power (VLF, $0.01 \mathrm{~Hz}$ to $0.04 \mathrm{~Hz}$, reflects activity of neurohumoral regulation). Further, K30/15, the ratio between maximal and minimal heart rate during the first 30 heart cycles of orthostatic test which reflects parasympathetic activity — was calculated.

Statistical analysis. All data were processed using the statistical package Statistica 6.0. Normal distribution of the obtained data was confirmed with Shapiro-Wilk's W-test. Normally distributed data are presented as means \pm standard deviation $(\mathrm{M} \pm \mathrm{m})$ and median (quartile range) for abnormally distributed parameters (most parameters of HRV).

The prevalence of $H$. pylori infection, inflammation, glandular atrophy and intestinal metaplasia, as well as incidence of HNE in gastric tissues, was evaluated by Chi-square test after classifying the marker as positive or negative. Possible difference in $H$. pylori contamination and intensity of HNE staining were done by MannWhitney U-test, using numerical description of positivity corresponding to respective standard grading of positivity as described above.

To compare means in groups (before and after IHT) paired samples $t$-test was employed. The $t$-test for independent variables was used to compare means between groups. Nonparametric Mann-Whitney U-test was used to compare HRV parameters.

\section{RESULTS}

Patients with DPUD predominantly had abdominal pain, signs of dyspepsia and asthenic neurotic syndrome, which were readily relieved by antibiotic treatment in both experimental groups. Infection with $H$. pylori was histologically confirmed in $73 \%$ DPUD patients in antrum and in $64 \%$ in corpus of the stomach $(P<0.001$ and $P=0.002$, respectively by $\chi^{2}$ test). In healthy volunteers $H$. pylori was found in $40 \%$ in antrum and in $35 \%$ in corpus of the stomach. The analysis according to the level of mucosal contamination did not show any significant difference between patients and control group with severe, moderate, and low degrees of contamination being observed in $19 \%, 32 \%$, and $50 \%$ of healthy volunteers and in $14 \%, 38 \%, 49 \%$ of DPUD patients, respectively $(P>0.05$ by Mann-Whitney U-test). Endoscopic study demonstrated that the majority of patients 

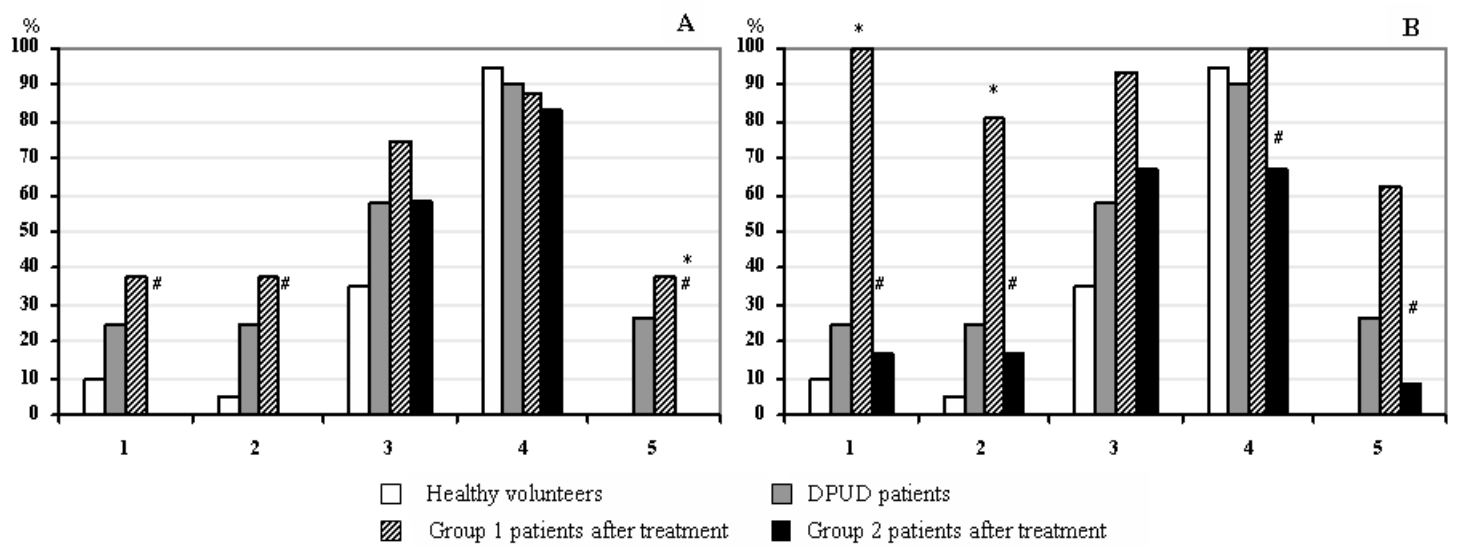

Figure 1. Content of HNE in the gastric mucosa of corpus and antrum of stomach: (A) corpus; (B) antrum.

Note: 1, superficial epithelium; 2, foveolar epithelium; 3, lamina propria; 4, glandular cytoplasm; 5, glandular nuclei; *difference significant before and after treatment, $P<0.05$; \#difference significant between DPUD groups after treatment, $P<0.05$.

$(96 \%)$ had ulcer of medium or large size associated with signs of gastritis and duodenitis with mild neutrophilic $(23 \%)$ and significant monocytic $(85 \%)$ infiltration, while in healthy volunteers infected with $H$. pylori only in a minority of cases neutrophilic (10\%) and monocytic (40\%) infiltration of the mucosa in gastric antrum were observed $\left(P=0.061\right.$ and $P<0.001$, respectively by $\chi^{2}$ test). Similar differences were observed in corpus of stomach. Eradication of $H$. pylori was achieved in more that $80 \%$ of patients in both groups, which was associated with a decrease in inflammation (lowering of neutrophils, monocytes, and lymphoid follicles count) of the mucosa in both study groups, however, these effects were more prominent in group 2. Healing of ulcer was observed in all treated patients, even in those with persistence of H. pylori.

Accumulation of $\mathrm{HNE}$ was demonstrated in superficial epithelium $(P<0.001)$, lamina propria $(P<0.001)$, and, what is of utmost importance, in nuclei of the glandulocytes $(P=0.022)$ in the antral part of the stomach in DPUD patients. The latter was not seen in the control group (Fig. 1A). Similar changes were observed in gastric corpus (Fig. 1B). Use of IHT in group 2 caused significantly better elimination of $\mathrm{HNE}$ from the structures of superficial and foveolar epithelium and its complete dis- appearance from the glandular nuclei. Increase in HNE content in both compartments of the stomach (Fig. 1A, B) especially prominent in the glandular nuclei was demonstrated in study group 1 . Redistribution of $\mathrm{HNE}$ according to the level of immunohistochemical positivity showed an increase in the number of patients with grade 0,1 , and 2 in the cytoplasm of group 2, while in group 1 patients with grade 3 dominated (Table 1 ).

The results of pro-anti-oxidant balance (oxidative homeostasis) in the blood of DPUD patients demonstrated an increased level of hydroperoxides, $\mathrm{OMP}_{430}$ and $\beta$-lipoproteins, a decrease in both fractions of MMM with close to normal values of CAT and SOD activities (Table 2). The eradication therapy resulted in strong decrease in CAT activity, normalization of hydroperoxides and $\mathrm{OMP}_{430}$ with some elevation of $\mathrm{MMM}$ in group 1 . In this group further increase in level of $\beta$-lipoproteins was observed, which is consistent with literature data about an increased risk of hyperlipidemia and obesity after eradication (Kamada et al., 2005). Such changes in group 1 are suggestive of a progressive decrease in redox reactions intensity and spread of oxidative stress signs to the level of the organism as a whole after treatment. Use of IHT in group 2 after eradication led to normalization of the hydroperoxide level, $\mathrm{OMP}_{430}$ and both MMM

Table 1. Subcellular HNE immunohistochemistry of gastric mucosa in DPUD patients before and after treatment

\begin{tabular}{|c|c|c|c|c|c|}
\hline \multirow[b]{2}{*}{ Morphological structures } & \multirow[b]{2}{*}{ Grade of positivity* } & \multicolumn{2}{|l|}{ Group 1} & \multicolumn{2}{|l|}{ Group 2} \\
\hline & & $\begin{array}{l}\text { Before treatment } \\
(n=18)\end{array}$ & $\begin{array}{l}\text { After treatment } \\
(n=16)\end{array}$ & $\begin{array}{l}\text { Before treatment } \\
(n=14)\end{array}$ & $\begin{array}{l}\text { After treatment } \\
(n=12)\end{array}$ \\
\hline \multirow[t]{4}{*}{ Glandular cytoplasm } & 0 & $0(0.0)^{* *}$ & $2(12.5)$ & $0(0.0)$ & $0(0.0)$ \\
\hline & 1 & $3(16.7)$ & $0(0.0)$ & $0(0.0)$ & $2(16.7)$ \\
\hline & 2 & $3(16.7)$ & $4(25.0)$ & $2(14.3)$ & $4(33.3)$ \\
\hline & 3 & $12(66.7)$ & $10(62.5)$ & $12(87.5)$ & $6(50.0)$ \\
\hline \multirow[t]{4}{*}{ Glandular nuclei } & 0 & $9(50.0)$ & $10(62.5)$ & $8(57.1)$ & $12(100.0)$ \\
\hline & 1 & $0(0.0)$ & $0(0.0)$ & $6(42.9)$ & $0(0.0)$ \\
\hline & 2 & $6(33.3)$ & $4(25.0)$ & $0(0.0)$ & $0(0.0)$ \\
\hline & 3 & $3(16.7)$ & $2(12.5)$ & $0(0.0)$ & $0(0.0)$ \\
\hline
\end{tabular}

Note: *semiquantitative staging as described in Material and Methods; ${ }^{* *}$ relative incidence values are given in brackets (\%) 
Table 2. Main indexes of aerobic metabolism in the blood and their changes with treatment in DPUD patients in blood

\begin{tabular}{|c|c|c|c|c|c|}
\hline \multirow{2}{*}{ Parameters } & \multicolumn{2}{|c|}{$\begin{array}{c}\text { DPUD } \\
\text { (group 1), } n=21\end{array}$} & \multicolumn{2}{|c|}{$\begin{array}{c}\text { DPUD } \\
\text { (group 2), } n=20\end{array}$} & \multirow{2}{*}{$\begin{array}{l}\text { Healthy volunteers, } \\
n=40\end{array}$} \\
\hline & 1 & 2 & 1 & 2 & \\
\hline Catalase, $\mu \mathrm{M} \mathrm{H}_{2} \mathrm{O}_{2} / \mathrm{ml} \times \mathrm{h}$ & $0.131 \pm 0.002$ & $0.115 \pm 0.003^{*}$ & $0.129 \pm 0.001$ & $0.153 \pm 0.001 *$ & $0.136 \pm 0.007$ \\
\hline SOD, $\%$ of inhibition & $11.38 \pm 1.44$ & $11.81 \pm 0.44$ & $12.31 \pm 0.73$ & $9.32 \pm 0.24^{* *}$ & $12.82 \pm 1.11$ \\
\hline TBARS, $\mu \mathrm{M} / \mathrm{ml}$ & $71.48 \pm 1.47$ & $70.87 \pm 1.84$ & $71.53 \pm 0.44$ & $78.43 \pm 0.50^{* \#}$ & $71.91 \pm 2.23$ \\
\hline $\mathrm{I}_{\mathrm{AOA}^{\prime}} \mathrm{CU}$ & $1.487 \pm 0.024^{\#}$ & $1.481 \pm 0.036$ & $1.490 \pm 0.02^{\#}$ & $1.419 \pm 0.011^{*}$ & $1.398 \pm 0.027$ \\
\hline$\beta$-LP, CU & $54.30 \pm 1.22$ & $67.11 \pm 0.67^{* \#}$ & $51.78 \pm 0.63$ & $52.35 \pm 0.28$ & $51.49 \pm 1.51$ \\
\hline Hydroperoxides, $\mathrm{U} / \mathrm{ml}$ & $2.44 \pm 0.03^{\#}$ & $1.65 \pm 0.02^{*}$ & $2.36 \pm 0.11^{\#}$ & $1.67 \pm 0.01^{* \#}$ & $1.51 \pm 0.08$ \\
\hline MMM, $254 \mathrm{~nm}, \mathrm{CU}$ & $182.6 \pm 1.9^{\#}$ & $262.7 \pm 4.3^{*}$ & $182.6 \pm 1.6^{\#}$ & $229.1 \pm 2.9^{*}$ & $241.4 \pm 8.7$ \\
\hline MMM, $280 \mathrm{~nm}, \mathrm{CU}$ & $230.5 \pm 3.9^{\#}$ & $297.1 \pm 8.0^{*}$ & $221.8 \pm 3.4 \#$ & $263.1 \pm 1.6^{*}$ & $270.5 \pm 12.0$ \\
\hline MMM 254/280, CU & $0.803 \pm 0.010^{\#}$ & $0.896 \pm 0.027^{*}$ & $0.828 \pm 0.016$ & $0.872 \pm 0.013$ & $0.911 \pm 0.023$ \\
\hline OMP, $370 \mathrm{~nm}, \mathrm{CU} / \mathrm{ml}$ & $5.18 \pm 0.15$ & $4.03 \pm 0.09^{* \#}$ & $5.16 \pm 0.05$ & $6.18 \pm 0.12^{* \#}$ & $4.97 \pm 0.19$ \\
\hline $\mathrm{OMP}, 430 \mathrm{~nm}, \mathrm{CU} / \mathrm{ml}$ & $2.22 \pm 0.08^{\#}$ & $1.23 \pm 0.06^{* \#}$ & $2.38 \pm 0.07^{\#}$ & $1.99 \pm 0.05^{* \#}$ & $1.63 \pm 0.07$ \\
\hline OMP, 370/430, CU & $2.34 \pm 0.08^{\#}$ & $3.42 \pm 0.17^{*}$ & $2.21 \pm 0.07^{\#}$ & $3.15 \pm 0.10^{*}$ & $3.21 \pm 0.15$ \\
\hline
\end{tabular}

Note: \#significant difference between healthy volunteers and DPUD, *significant difference before and after treatment is, $P<0.05$; values are given as mean \pm standard deviation, 1 , before treatment; 2 , after treatment.

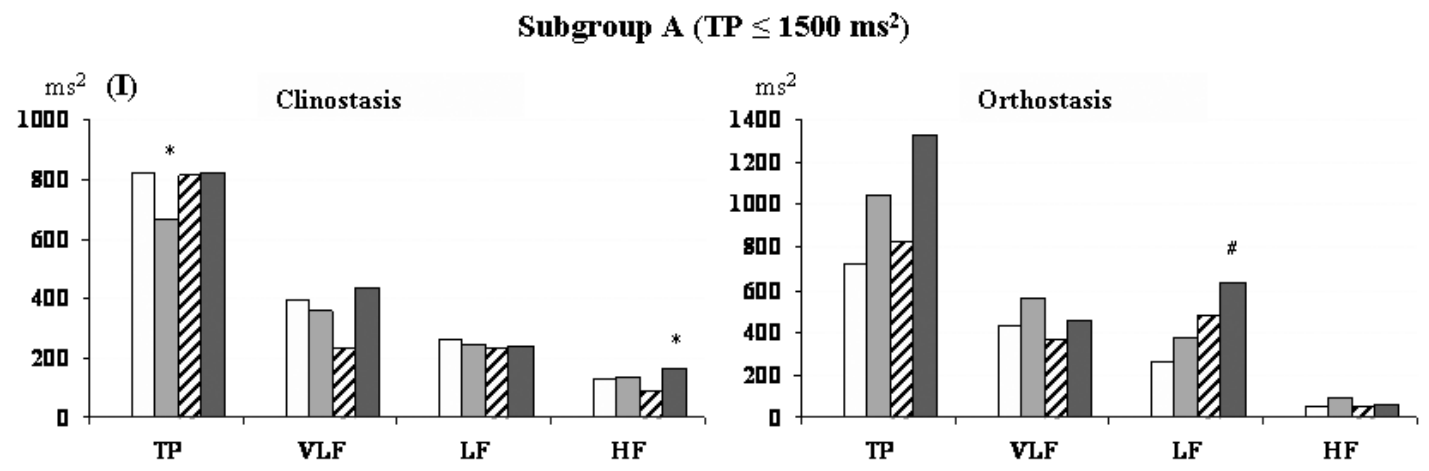

Subgroup $B\left(T P>1500 \mathrm{~ms}^{2}\right)$

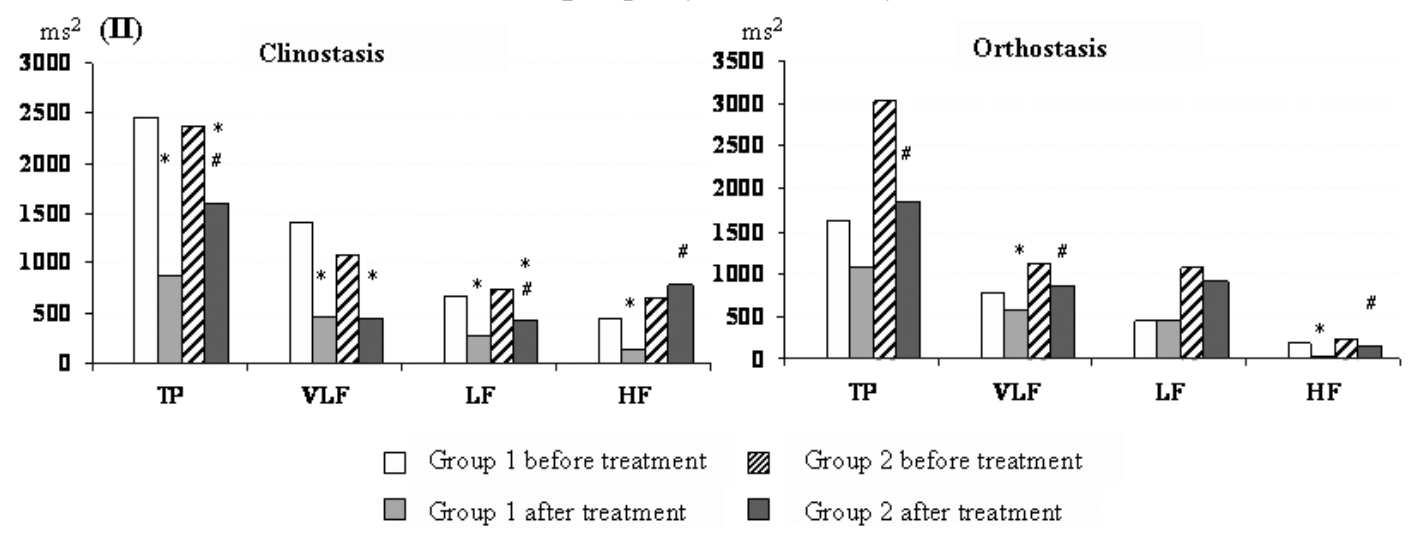

Figure 2. Dynamics of HRV in H. pylori-associated DPUD before and after standard eradication therapy and use of IHT.

Patients with initially low HRV parameters (panel (I), subgroup A) and initially high HRV parameters (panel (II), subgroup B). Note: ${ }^{*}$ difference significant before and after treatment, $P<0.05$; \#significant difference between DPUD groups after treatment, $P<0.05$; TP, total power; VLF, very low frequency power; LF, low frequency power; HF, high frequency power. 
Table 3. Changes in autonomic balance (LF/HF) in DPUD patients with standard and study therapy

\begin{tabular}{|c|c|c|c|c|c|c|c|c|}
\hline \multirow{3}{*}{ LF/HF } & \multicolumn{4}{|l|}{ Group 1} & \multicolumn{4}{|l|}{ Group 2} \\
\hline & \multicolumn{2}{|l|}{$\begin{array}{l}\text { Subgroup A } \\
n=22\end{array}$} & \multicolumn{2}{|l|}{$\begin{array}{l}\text { Subgroup B } \\
n=18\end{array}$} & \multicolumn{2}{|l|}{$\begin{array}{l}\text { Subgroup A } \\
n=15\end{array}$} & \multicolumn{2}{|l|}{$\begin{array}{l}\text { Subgroup B } \\
n=20\end{array}$} \\
\hline & 1 & 2 & 1 & 2 & 1 & 2 & 1 & 2 \\
\hline Clinostasis & $1.80(3.00)$ & $\begin{array}{l}1.31(1.89) \\
P=0.024\end{array}$ & $1.43(1.44)$ & $\begin{array}{l}2.56(0.81) \\
P=0.000\end{array}$ & $2.04(1.93)$ & $\begin{array}{l}1.75(1.79) \\
P=0.026\end{array}$ & $1.28(1.20)$ & $\begin{array}{l}1.15(1.44) \\
P=0.187\end{array}$ \\
\hline Orthostasis & $7.16(6.18)$ & $\begin{array}{l}5.68(6.95) \\
P=0.105\end{array}$ & $5.80(3.71)$ & $\begin{array}{l}12.91(6.12) \\
P=0.000\end{array}$ & $6.96(8.07)$ & $\begin{array}{l}7.11(5.11) \\
P=0.233\end{array}$ & $3.38(4.76)$ & $\begin{array}{l}4.38(7.40) \\
P=0.541\end{array}$ \\
\hline
\end{tabular}

Note: 1 , before treatment; 2 , after treatment. Median (quartile range) are given.

fractions, while the level of TBARS and OMP 3 were slightly increased. Simultaneously, modulation of the activity of main antioxidant enzymes with a significant increase in CAT activity and lowering of SOD activity was observed (Table 2).

Study of HRV demonstrated that patients with DPUD had lower both time (SDNN, RMSSD, pNN50 $(P<0.001))$ and frequency $(\mathrm{TP}, \mathrm{LF}, \mathrm{HF}(P<0.001) \mathrm{VLF}$ $(P=0.103))$ domain parameters comparing to healthy subjects, which denotes low activity of the autonomic nervous system and a decrease in the adaptive potential of the organism. Because HRV index values were individual and highly varied (TP ranged from $600 \mathrm{~ms}^{2}$ to $14000 \mathrm{~ms}^{2}$ ), to demonstrate the mechanisms of IHT effects patients of both groups were divided into two subgroups. Subgroup A included subjects with initially low HRV (TP in clinostasis $\leq 1500 \mathrm{~ms}^{2}$ ), while subgroup $\mathrm{B}$ included those with TP $>1500 \mathrm{~ms}^{2}$ in clinostasis. As a result, different changes of HRV parameters in patients with initially high and in those with initially low TP were demonstrated. After standard therapy subgroup A group 1 patients showed a decrease in TP and all frequency components in supine position (Fig. 2). However, that was accompanied by a decrease in sympathovagal index suggesting normalization of autonomic balance (Table 3) and an increase in all frequency parameters during orthostatic test (Fig. 2). Use of IHT in subgroup A not only prevented the decrease of HRV but also caused activation of central and autonomic regulatory mechanisms both in clinostasis and orthostasis (Fig. 2) with minimal changes in the $\mathrm{LF} / \mathrm{HF}$ ratio (Table 3). In group 1 subgroup B the standard therapy caused a marked decrease in TP and all spectral indexes VLF, $\mathrm{LF}$, and $\mathrm{HF}$ ), both in orthostasis and clinostasis. Moreover, prominent activation of sympathetic nervous system (LF) comparing to parasympathetic (HF) especially in orthostasis was observed (Table 3). In contrast, group 2 subgroup $\mathrm{B}$ individuals had a less prominent decrease in TP, which was associated with an improvement of spectrum structure $(\uparrow \mathrm{HF}$ and $\uparrow \mathrm{LF}$ comparing to group 1 patients with similar HRV) and relief of neurohumoral strain ( $\downarrow$ VLF). Activation of parasympathetic nervous system and normalization of the LF/HF balance were also observed.

Thus, use of IHT in complex treatment of H. pyloriassociated DPUD resulted not only in a more efficient correction of inflammatory changes in the gastric and duodenal mucosa, but also in better elimination of the OS marker HNE from the histological structures of the stomach. At the level of the organism the use of IHT improved the adaptive potential as described by the dynamics of the HRV parameters and simultaneous mild prooxidant activation of aerobic metabolism.

\section{DISCUSSION}

Nowadays, peptic ulcer is recognized as multifactorial illness, the pathogenesis of which is closely related to H. pylori infection (Suerbaum \& Michetti, 2002; Malaty, 2007). There is extensive literature data showing OS to be the leading factor in $H$. pylori-induced mucosal injury (Matthews \& Butler, 2005; Augusto et al., 2007). However, evidence about the important role of host defense factors in the development of the disease as well as its

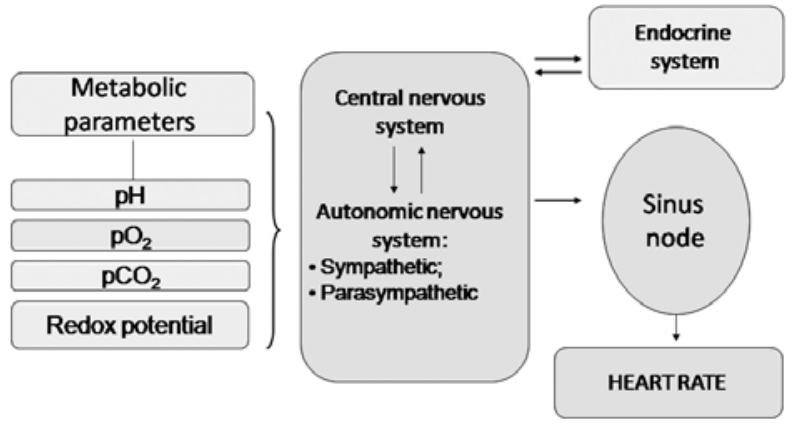

Figure 3. Relationships between the activity of sinus node (indexes of HRV) and metabolic parameters.

The activity of sinus node depends on the functioning of the central and autonomic nervous systems, and endocrine system which, in turn, are strongly influenced by a number of metabolic parameters $\left(\mathrm{pO}_{2}, \mathrm{pH}, \mathrm{pCO}_{2}\right.$, and redox potential). Evidence supporting this concept include facts that the function of the carotid body, which is believed to act as an oxygen sensor, is closely involved in the modulation of the activity of the autonomic nervous system on the heart (Prabhakar et al., 2005; Yelisyeyeva et al., 2005; Mangoni \& Nargeot, 2008), while the performance of the higher centers of endocrine regulation (hypothalamus) is tightly related by feedback mechanisms to the main homeostatic constants (glucose, $\mathrm{pH}, \mathrm{pO}_{2}, \mathrm{pCO}_{2}$, etc.). Therefore, the resulting integrated influence on the sinus node indirectly reflects redox balance and aerobic metabolism in the body. We propose that, when the OS is abated by the efficient functioning of aerobic metabolism, the strain on the cardiovascular system is relieved and the heart rate decreases. Efficient activators of aerobic metabolism (such as IHT in this study) can induce a functional shift in the metabolic system to a higher level of intensity (with better coupling between catabolism and anabolism, and more potent ROS production). Thus, longer maintenance of homeostatic metabolic constants due to improved functioning of aerobic metabolism and its autonomic regulation with optimized function of the cardiac rhythm can be achieved. Under such circumstances, the drive of the autonomic nervous system is activated ( $\uparrow L F, H F$ of HRV), while the involvement of central and endocrine regulatory mechanisms ( $\downarrow$ VLF) becomes limited. In case signs of the OS persist, the shifts of main metabolic constants can not be compensated at the biochemical level and more intense involvement of the neurohumoral regulation is required ( $\uparrow$ VLF). Thus, profound OS, when not treated for a long time, would result in excessive load on the cardiovascular system with subsequent lowering of all time and frequency domain HRV indexes and the adaptive potential of the organism. 


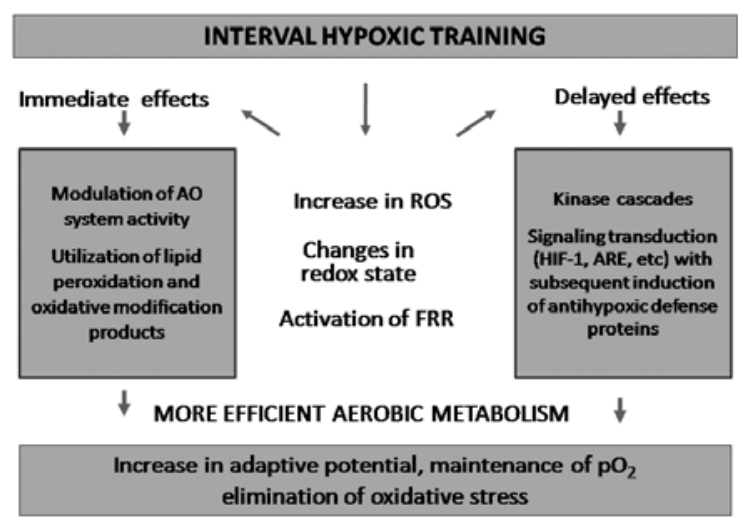

Figure 4. Main effects of interval hypoxic training.

IHT comprises repetitive sessions of breathing with hypoxic mixture interspersed with periods of room-air breathing and acts through the mechanism of preconditioning, which denotes exposure to a mild stressor making an organism more resistant to severe stress. IHT initiates increase in ROS flow, changes the redox state in the cells, and activates FRR. This, in turn, triggers immediate and delayed reactions. Because the activation of FRR is associated with production of $\mathrm{O}_{2}$ (Tymochko et al., 1998), the immediate effects of IHT include increase in the activity of antioxidant defense enzymes, which are predominantly oxygen dependent, resulting in better utilization of oxidative destruction products. Delayed effects require activation of cellular signaling machinery which leads to the synthesis of antihypoxic defense proteins. The interval exposure to hypoxia during IHT prevents excessive formation of ROS and exhaustion of antioxidant defense mechanisms. Thus, the improved functioning of aerobic metabolism and maintenance of $\mathrm{pO}_{2}$, observed due to $\mathrm{IHT}$, facilitates elimination of OS and better regeneration of damaged cellular structures.

healing also exists (Khomenko et al., 2004; Matthews \& Butler, 2005). That was further proved by our studies demonstrating that healthy volunteers infected with H. pylori did not show prominent signs of inflammation in gastric mucosa (Yelisyeyeva et al., 2008). In the current study we found that they had less HNE-protein adducts in gastric mucosa, while peptic ulcer was associated not only with accumulation of this OS marker in the mucosa, but also with significant pro/antioxidant imbalance in the blood. A decrease in the functional metabolic potential of the DPUD patients was proved by lower time and frequency domain indexes of HRV. Thus, development of DPUD in $H$. pylori-infected subjects, in our opinion, was closely related to the general decrease in the intensity of redox processes and spreading of the OS to the level of the whole organism.

Currently, standard therapy of $H$. pylori-related DPUD is primarily aimed at eradication of this microorganism. It is known, on the other hand, that drugs commonly used for the eradication exhibit some antioxidant properties, which helps to decrease, but does not eliminate the signs of OS after treatment (Everett et al., 2001; Cherkas et al., 2009). In our study, it was shown that successful eradication therapy was followed by a marked increase in the amount of HNE associated with redistribution of its content towards higher grades of immunopositivity in the gastric mucosa and persistence of this important OS marker in glandular nuclei. Such changes were associated with further decrease in the aerobic metabolism intensity of DPUD patients with treatment as evidenced by the significant decrease in CAT activity associated with increased level of atherogenic $\beta$-lipoproteins and MMM. Simultaneously, the level of OMP, which reflects the intensity of aerobic metabolism decreased significantly, even below normal values. In clinical practice such meta- bolic situation could result in recurrence of clinical manifestations and relapse of ulcer during the course of the disease.

Our findings together with literature data substantiate the use of remedies with antioxidant properties in complex treatment of DPUD. One of the promising approaches is IHT, which is one of the best methods used to enhance the adaptive potential of an organism (Bernardi et al., 2001; Morton \& Cable, 2005; Prabhakar et al., 2005 ; 2007). It is widely accepted that the effects of IHT are related to the increase in free radical production with the subsequent induction of the antioxidant defense. It should also be mentioned that IHT predominantly affects aerobic metabolism intensity and coupling and can increase oxygen fluctuations during activated enzymatic and non-enzymatic FRR (Tymochko et al., 1998; Voeikov, 2005). FRR are known to be poorly controlled and branching by their nature, therefore, the duration of hypoxic exposures during IHT should be minimized. Optimal timing of hypoxic sessions during IHT allows the reinforcement of the mechanisms of endogenous oxygen and ROS production, improvement in coupling between catabolism and anabolism, and, thus, achieving higher level of adaptation (Fig. 4).

Introduction of IHT in DPUD patients caused more efficient elimination of clinical manifestations and inflammation in gastric and duodenal mucosa as witnessed by the gross appearance of the gastroduodenal region and a decrease in mononuclear count on histological examination comparing to group 1. Moreover, group 2 patients demonstrated significantly better elimination of HNE from the structures of superficial and foveolar epithelium and, notably its complete disappearance from the glandular nuclei. These results are of great value also because of the dualistic properties of HNE, which in large concentrations exhibits genotoxic effects, while in low physiological amount serves as an important signaling molecule (Uchida, 2003; Zarkovic, 2003). In particular the removal of HNE from the nuclear region of the cell might be important since it was found recently that location of $\mathrm{HNE}$ in the nuclear region might be associated with carcinogenesis (Marquez-Quiñones et al., 2010).

Efficient elimination of OS signs from the gastrointestinal tract in our patients appeared to be associated with development of mild prooxidant activity at the systemic level. The observed mild increase in TBARS and OMP with a decline in SOD activity may facilitate an involvement of superoxide radical in FRR and, thus, prevent inhibition of FRR and accumulation of oxidative destruction products. A mild prooxidant activity, because of Michael adducts-like properties of lipid peroxidation products, is also essential for initiation of the signal transduction pathways (HIF-1, Nrf2, NF- $x \mathrm{~B}$, etc.) aimed at the maintenance of redox balance, membrane potential, and antioxidant defense (Das \& Maulik, 2003; 2006; Zarember \& Malech, 2005; Ellis, 2007). This is a prerequisite for improvement of the adaptive potential and, therefore, efficient regeneration and healing in DPUD patients. Of note is also a decrease in $\beta$-lipoprotein level observed with IHT treatment, which proves its efficacy as a tool to reduce the risk of hyperlipidemia observed after eradication in the present and other studies (Kamada et al., 2005).

The ability of IHT to improve functional metabolic potential was demonstrated by modulation of HRV parameters. In patients from subgroup A with initially low HRV indexes group 2 IHT prevented further decrease in time and frequency domain indexes (observed in sub- 
group A group 1) mainly on account of activation of neurohumoral and autonomic components. Similar positive changes were found during orthostatic test, suggesting increased nonspecific resistance and elimination of $\mathrm{OS}$ in these subjects. Even more efficient modulation of HRV with IHT was observed in subgroup B with initially high IHT indexes. In comparison with similar patients who did not practice IHT, a mild decrease in TP was associated with marked improvement of frequencydomain parameters, especially HF power, which reflects the activity of parasympathetic nervous system. During orthostatic test in these individuals autonomic balance, as indicated by the LF/HF ratio, did not change significantly, while in subgroup B group 1 patients it increased reflecting a loss of the mobilization phase of adaptive reaction. The latter could be associated with worse prognosis for healing of the ulcer and maintenance of remission. Moreover, it is known that high parameters of HRV with high VLF and low HF- and LF-power are suggestive of strain of the central regulation, which may caused progression of autonomic imbalance (Prabhakar et al., 2005; Yelisyeyeva et al., 2005; Mangoni \& Nargeot, 2008). Thus, the ability of IHT to modulate autonomic homeostasis might indicate improvement of functional metabolic reserve (Fig. 3). As it is seen from the scheme modulation of main metabolic constants is readily reflected in the activity of the sinus node. Thus, elimination of the signs of OS and cellular hypoxia during activation of aerobic metabolism results in improved HRV parameters and, therefore, general resistance of the regulatory systems to external and internal insults.

To conclude, there is accumulating evidence that standard eradication therapy in patients with $H$. pylori-associated DPUD should be complemented with remedies which stimulate redox reactions and, thus, increase the resistance to $\mathrm{OS}$ and modulate autonomic balance and oxidative homeostasis, as it is shown here for IHT.

\section{Acknowledgements}

This study is dedicated to the memory of our teacher Professor Mykhailo Tymochko who devoted many years of his life to research on beneficial and harmful effects of hypoxia.

Many thanks to the Croatian Ministry of Science and Sports and COST B35 Action for the support.

\section{REFERENCES}

Arumugam TV, Gleichmann M, Tang SC, Mattson MP (2006) Hormesis/preconditioning mechanisms, the nervous system and aging. Ageing Res Rev 5: 165-178.

Augusto AC, Miguel F, Mendonca S, Pedrazzoli J Jr, Gurgueira SA (2007) Oxidative stress expression status associated to Helicobacter $p y^{-}$ lori virulence in gastric diseases. Clin Biochem 40: 615-622.

Bell EL, Emerling BM, Chandel NS (2005) Mitochondrial regulation of oxygen sensing. Mitochondrion 322-332.

Bernardi L, Passino C, Serebrovskaya Z, Serebrovskaya T, Appenzeller O (2001) Respiratory and cardiovascular adaptations to progressive hypoxia; effect of interval hypoxic training. Eur Heart J 22: 879-886.

Bunn HF, Poyton RO (1996) Oxygen sensing and molecular adaptation to hypoxia. Physiol Rev 76: 839-885.

Cherkas A, Yelisyeyeva O, Semen K, Zarkovic K, Kaminskyy D, Gasparovic AC, Jaganjac M, Lutsyk A, Waeg G, Zarkovic N (2009) Persistent accumulation of 4-hydroxynonenal-protein adducts in gastric mucosa after Helicobacter pylori eradication. Coll Antropol 33: $815-821$.

Connes P, Hue O, Hardy-Dessources MD, Boucher JH, Pichot V, Barthelemy JC (2008) Hemorheology and heart rate variability: is there a relationship? Clin Hemorbeol Microcirc 38: 257-265.
Das DK, Maulik N (2003) Preconditioning potentiates redox signaling and converts death signal into survival signal. Arch Biochem Biophys 420: $305-311$.

Das DK, Maulik N (2006) Cardiac genomic response following preconditioning stimulus. Cardiovasc Res 70: 254-263.

Denisov ET, Afanas'ev IB (2005) Oxidation and antioxidants in organic chemistry and biology. Taylor \& Francis Group, Boca Raton.

Dubinina E, Burmistrov S, Khodov D, Porotov I (1995) Oxidative modification of human blood serum proteins: a method for its estimation. Vopr Med Cbimii 41: 24-29 (in Russian).

Ellis EM (2007) Reactive carbonyls and oxidative stress: potential for therapeutic intervention. Pharmacol Ther 115: 13-24.

Everett SM, Singh R, Leuratti C, White KL, Neville P, Greenwood D, Marnett LJ, Schorah CJ, Forman D, Shuker D, Axon AT (2001) Levels of malondialdehyde-deoxyguanosine in the gastric mucosa: relationship with lipid peroxidation, ascorbic acid, and Helicobacter pylori. Cancer Epidemiol Biomarkers Prev 10: 369-376.

Giordano FJ (2005) Oxygen, oxidative stress, hypoxia, and heart failure. J Clin Invest 115: 500-508.

Gurusamy N, Lekli I, Gorbunov NV, Gherghiceanu M, Popescu LM, Das DK (2009) Cardioprotection by adaptation to ischaemia augments autophagy in association with BAG-1 protein. J Cell Mol Med 13: 373-387.

Guzy RD, Schumacker PT (2006) Oxygen sensing by mitochondria at complex III: The paradox of increased ROS during hypoxia. Exp Physiol 91: 807-819.

Haensel A, Mills PJ, Nelesen RA, Ziegler MG, Dimsdale JE (2008) The relationship between heart rate variability and inflammatory markers in cardiovaskular diseases. Psychoneuroendocrinology 33: 1305-1312.

Task Force of the European Society of Cardiology and the North American Society of Pacing and Electrophysiology (1996) Heart rate variability. Standards of measurement, physiological interpretation, and clinical use. Eur Heart J 17: 354-381.

Jones DP (2006) Disruption of mitochondrial redox circuitry in oxidative stress. Chem Biol Interact 163: 38-53.

Kamada T, Hata J, Kusunoki H, Ito M, Tanaka S, Kawamura Y, Chayama K, Haruma K (2005) Eradication of Helicobacter pylori increases the incidence of hyperlipidaemia and obesity in peptic ulcer patients. Dig Liver Dis 37: 39-43.

Kamyshnikov VS (ed) (2000) Reference on clinical biochemical laboratory diagnostics (in 2 vol). Minsk: Belarus: a, vol 1: 344-351; b, vol 2: 323-325; c) vol. 2: 334-342

Katayama K, Fujita H, Sato K, Ishida K, Iwasaki K-I, Miyamura M (2005) Effect of a repeated series of Intermittent hypoxic exposures on ventilatory response in humans. High Alt Med Biol 6: 50-59.

Kawada T, Mizuno M, Shimizu S, Uemura K, Kamiya A, Sugimachi M (2009) Angiotensin II disproportionally attenuates dynamic vagal and sympathetic heart rate controls. Am J Physiol Heart Circ Physiol 296: H1666-H1674.

Khomenko T, Deng X, Sandor Z, Tarnawski AS, Szabo S (2004) Cysteamine alters redox state, HIF-1a transcriptional interactions and reduces duodenal mucosal oxygenation: novel insight into the mechanisms of duodenal ulceration. Biochem Biophys Res Commun 317: 121-127.

Korolyuk M, Ivanova L, Mayorova I, Tokarev V (1998) A method for measuring catalase activity. Lab Delo 16-19 (in Russian).

Kostyuk V, Potapovich A, Kovaleva Z (1990) A simple sensitive assay for determination of superoxide dismutase activity based on reaction of quercetin oxidation. Vopr Med Khimii 88-91 (in Russian).

Levine BD (2002) Intermittent hypoxic training: fact and fancy. High Alt Med Biol 3: 177-193.

Malaty HM (2007) Epidemiology of Helicobacter pylori infection. Best Pract Res Clin Gastroenterol 21: 205-214.

Mangoni ME, Nargeot J (2008) Genesis and regulation of the heart automaticity. Physiol Rev 88: 919-982.

Manoli I, Alesci S, Blackman MR, Su YA, Rennert OM, Chrousos GP (2007) Mitochondria as key components of the stress response. Trends Endocrinol Metab 18: 190-198.

Marquez-Quinones A, Cipak A, Zarkovic K, Fateel-Fazenda S, VillaTrevino S, Waeg G, Zarkovic N, Gueraud F (2010) HNE-protein adducts formation in different pre-carcinogenic stages of hepatitis in LEC rats. Free Radic Res 44: 119--.

Matthews GM, Butler RN (2005) Cellular mucosal defense during Helicobacter pylori infection: a review of the role of glutathione and the oxidative pentose pathway. Helicobacter 10: 298-306.

Mattson MP (2008) Hormesis defined. Ageing Res Rev 7: 1-7.

Morton JP, Cable NT (2005) The effects of intermittent hypoxic training on aerobic and anaerobic performance. Ergonomics 48: 15351546.

Neubauer JA (2001) Physiological and genomic consequences of intermittent hypoxia. Invited review: physiological and pathophysiological responses to intermittent hypoxia. J Appl Physiol 90: 1593-1599.

Packer L, Cadenas E (2007) Oxidants and antioxidants revisited. New concepts of oxidative stress. Free Radic Res 41: 951-952. 
Pongchaidecha A, Lailerd N, Boonprasert W, Chattipakorn N (2009) Effects of curcuminoid supplement on cardiac autonomic status in high-fat-induced obese rats. Nutrition 25: 870-878.

Prabhakar NR (2001) Oxygen sensing during intermittent hypoxia: cellular and molecular mechanisms. J Appl Physiol 90: 1986-1994.

Prabhakar NR, Peng YJ, Jacono FJ, Kumar GK, Dick TE (2005) Cardiovascular alterations by chronic intermittent hypoxia: importance of carotid body chemoreflexes. Clin Exp Pharmacol Physiol 32: 447449.

Prabhakar NR, Kumar GK, Nanduri J, Semenza GL (2007) ROS signaling in systemic and cellular responses to chronic intermittent hypoxia. Antioxid Redox Signal 9: 1397-1403.

Suerbaum S, Michetti P (2002) Helicobacter pylori infection. N Engl J Med 347: 1175-1186.

Timirbulatov R, Seleznev E (1986) Methods for increasing intensity of free radical oxidation of blood lipids containing components and its diagnostic value. Lab Delo 4: 209-211 (in Russian).

Tymochko M, Kobylinska LI., Aleksevych YI. (1998) The role of free radical reactions in formation of the organism's oxygen homeostasis. Hypoxia Medical J 6: 154-158.

Uchida K (2003) 4-hydroxynonenal: a product and mediator of oxidative stress. Prog Lipid Res 42: 318-343.

Voeikov VL (2005) Biological oxidation: over a century of hardship for the concept of active oxygen. Cell Mol Biol 51: 663-675. von Kanel R, Thayer JF, Fischer JE (2009) Nighttime vagal cardiac control and plasma fibrinogen levels in a population of working men and women. Ann Noninvasive Electrocardiol 14: 176-184.

Waeg G, Dimisity G, Esterbauer H (1996) Monoclonal antibodies for detection of 4-hydroxynonenal modified proteins. Free Radic Res 25: 149-159.

Williams SE, Wootton P, Mason HS, Bould J, Iles DE, Riccardi D, Peers C, Kemp PJ (2004) Hemoxygenase-2 is an oxygen sensor for a calcium-sensitive potassium channel. Science 306: 2093-2097.

Yelisyeyeva O, Serhiyenko O, Cherkas A, Semen K, Kaminskyy D, Kurkevych A (2005) Heart rate variability in patients with diabetes mellitus: an attempt of metabolic interpretation. Probl Endocrine Pathol 95-110 (in Ukrainian).

Yelisyeyeva O, Cherkas A, Zarkovic K, Semen K, Kaminskyy D, Waeg G, Zarkovic N (2008) The distribution of 4-hydroxynonenal-modified proteins in gastric mucosa of duodenal peptic ulcer patients. Free Radic Res 42: 205-211.

Zarember KA, Malech HL (2005) HIF-1a: a master regulator of innate host defenses? Am Soc Clin Invest 1702-1704.

Zarkovic N (2003) 4-Hydroxynonenal as a bioactive marker of pathophysiological processes. Mol Aspects Med 24: 281-291. 